\title{
Dolores y los entramados del olvido
}

\section{Dolores and treatment of the forget}

\section{Bracamonte Gómez, Carolina; Perusia, Claudio; Graglia, María Soledad ${ }^{1}$}

Resumen. En este trabajo proponemos algunas reflexiones en torno al proceso analítico entre Dolores y un analista. Nos preguntamos: ¿Cuáles son los modos en que se configuran en el campo analítico las representaciones y lo no-representado? ¿Cómo integrar/tejer/entramar allí lo sentido y lo pensado?. Postulamos, como hipótesis, que algunos afectos -huellas de aquello no representado- son mudos para el paciente, pero son susceptibles de ser pesquisados mediante las propias sensaciones del analista, a partir de ciertos indicadores emocionales del campo. La disposición del analista y su propio aporte representacional serán necesarios para configurar un encuentro senti-pensante que potencie la integración de lo sentido aun cuando no ha podido ser pensado y lo acoja en un espacio transicional, que no está en la mente del paciente ni tampoco en la del analista, las implica a ambas, y a su vez las excede.

Palabras Clave: campo analítico - proceso psicoanalítico - encuentro -contratransferencia sentipensante.

\footnotetext{
1 Bracamonte Gómez, Carolina. Lic. Psicología (UNC). Especialista en Psicología Clínica (Colegio de Psicólogos de la Pcia. de Córdoba, ME: 501). Maestranda en Investigación e Intervención PsicoSocial (tesis en proceso, UNC). Jefa de Trabajos Prácticos, Cátedra Intervenciones Psicológicas desde una Perspectiva Psicoanalítica (Psicología, UCC) y Cátedra Prácticas Profesionales Supervisadas (Psicología, UCC). Integrante de equipo de investigación: El psicoanálisis en carreras de psicología, su influencia en la formación de psicólogo en Argentina (1958-1988), (Psicología, UCC). Córdoba, Argentina. carobracamontegomez@ hotmail.com

Perusia, Claudio. Lic. Psicología (UNC). Psicoanalista. Miembro Titular con Función Didáctica (IPA). Maestrando en Psicoanálisis (Tesis en proceso, USAL-APA). Doctorando en Psicología (Tesis en proceso, USAL-APA). Integrante del Equipo Docente del Seminario Freudiano (APC).Profesor Titular Cátedra Intervenciones Psicológicas desde una Perspectiva Psicoanalítica (Psicología, UCC). Integrante de equipo de investigación: El psicoanálisis en carreras de psicología, su influencia en la formación de psicólogo en Argentina (1958-1988), (Psicología, UCC). Córdoba, Argentina. clasiperu@ hotmail.com

Graglia, María Soledad. Lic. Psicología (UNC). Especialista en Gestión de Instituciones Sociales (FLACSO). Maestranda en Antropología (UNC). Profesora Titular cátedra de Teoría psicoanalítica III (Psicología, Universidad Siglo 21). Profesora asociada Cátedra de Psicología Social (Comunicación, Universidad Blas Pascal). Miembro del Espacio Infancias, redes y miradas actuales (UNC). Córdoba, Argentina. soledadgraglia@gmail.com
}

Debates actuales en Psicología y Sociedad. ISSN en línea: 2591-524X

Año II, № 2, 2019. Pág. 53-59.

DOI: 10.22529/daps.2019.2(2)04 / Recibido: 23-9-2019 / Aprobado: 7-11-2019.

Artículo publicado bajo Licencia Creative Commons Atribución-NoComercial-SinDerivar. (C) Universidad Católica de Córdoba. 


\begin{abstract}
In this paper we propose some reflections on the analytical process between Dolores and an analyst. We ask ourselves: What are the ways in which representations and non-representations are configured in the analytical field? How to integrate / weave / enter the feeling and thought there? We postulate, as a hypothesis, that some affections - footprints of that not represented - are mute for the patient, but are likely to be investigated through the analyst's own sensations, based on certain emotional indicators of the field. The disposition of the analyst and his own representational contribution will be necessary to set up a sentipensante meeting that enhances the integration of the sense even when it has not been possible to think about it and embraces it in a transitional space, which is neither in the patient's mind nor in that of the analyst, it implies both, and in turn exceeds them.
\end{abstract}

Keywords: analytical field - psychoanalytic process - meeting -countertransference sentipensante 
Pupe dejando Europa y a su marido, con dos hijos pequeños, se instaló en estas tierras. Frecuentando la iglesia, conoce a un joven sacerdote español, Pepe, quien se enamora más de esos dos chiquitos que de la mujer alta y rubia que los llevaba de la mano. Por cosas de las que no podremos dar cuenta, ambos (el joven curita y la viuda) deciden casarse.

Al paso de los años, Pupe se había tornado más rígida y prejuiciosa. Era ya una anciana con dos hijos universitarios y un esposo apenas mayor que ellos. En ese momento, recibe a su sobrina con sus 2 hijos (una niña de 9 años, Dolores, y su hermano de 5),quien había enviudado recientemente y le habían diagnosticado una enfermedad con pronóstico poco alentador. Temiendo por el bienestar de sus hijos, acude a su única tía. Sin embargo, no es Pupe quien se conmueve con la viuda, sino el tío Pepe. Él la acompaña y la asiste, tomando casi el lugar de padre para sus hijos. Situación que no es grata para Pupe y que no oculta, aunque tampoco puede evitar. Así, Pepe se convirtió en el principal respaldo de la mamá viuda de estos chicos que además de una precaria salud, tenía una mala situación económica: maestra, con muchos gastos médicos y dos hijos pequeños a cargo.

Al cabo de unos años, la tía Pupe falleció y al poco tiempo, también muere la mamá de Dolores, quién tenía 21 años y quedaba de este modo como tutor legal de su hermano, aún menor de edad. Dolores no tiene recuerdos claros de aquellos momentos, pero dice que cuando su tío (que tenía más de 50 años) le pidió matrimonio, ella en primer lugar le dijo que no podían porque él era su tío, pero cuando él le explicó, que en realidad solamente era una relación política y no de sangre, finalmente accedió, asumiendo que no tenía más opción. El casamiento se concretó al poco tiempo: una ceremonia sencilla y con muy pocos invitados tras lo cual la pareja se trasladó a la casa de la tía Pupe. Recuerda que, al entrar, con su única maleta, volvió a ver el enorme cuadro familiar en el centro del recibidor: su tía joven y hermosa, rodeado de sus hijos y su marido... hoy, su marido. El cuadro no fue removido, ni ningún otro mobiliario de la casa cambiado de lugar. Para ella nada se había movido...

Pasaron más de 20 años. Dolores es ya una mujer de poco más de 40 cuando acude a la consulta. Llega por indicación insistente de una compañera de trabajo. En la primera entrevista, su aspecto es el de una mujer abatida, de cabello oscuro, muy corto, contextura pequeña, delgada y de aspecto sencillo. Refiere que recientemente se ha separado de su marido. Desencadenó su decisión que éste amenazó con un arma al hijo mayor de ambos, de 21 años, frente a ella y a la hija menor. Dice que entonces, tomó a sus hijos y se fueron de la casa, que no lo pensó. Luego se desencadenaron una serie de situaciones que ella no alcanza a 
pensar, las personas cercanas hablan de maltrato y le indican acciones a seguir, pero siente que ella no puede ejecutarlas. Duda si no será mejor volver...Su marido desde hace tiempo se ha vuelto violento, pero nunca pensó que podría llegar a este extremo. Nadie del círculo familiar íntimo lo pensaba... Ante la separación, su hermano le dice: "cómo pudiste hacerle esto al tío?!”.

No puede pensar lo sucedido ni tampoco plantea una demanda de análisis. Quizás el encuentro en el consultorio entre una persona y un analista, no supone de inicio la instauración de un campo operando en el sentido barangeriano. El encuentro desencadena una tormenta emocional en la que hay que encontrar la mejor manera de pasar el mal trago (Bion, 1992). Nos preguntamos: ¿cómo se construye entonces, en esa relación bipersonal un campo analítico en el que emerjan, a partir del encuentro mismo, un paciente y un analista como funciones operantes en dicho campo?

La paciente vuelve: ¿por qué vuelve? ¿Qué encuentra para volver? ¿Encuentra un lugar donde otro la aloja? ¿Un espacio para poder pensar lo que nunca fue pensado? Al inicio probablemente la presencia del analista solo "soporta" y recibe junto con la paciente también sus sin sentidos, la confusión, la emocionalidad que desborda y no encuentra palabra ni pensamiento, el vacío; tolera la incertidumbre. Se comienza a configurar un campo. ¿El encuentro va a producir el campo? ¿De qué encuentro estaríamos hablando entonces? ¿Cuáles son los procesos que intervienen en su producción?...si tenemos en cuenta que la génesis del padecimiento psíquico deriva del grado de disponibilidad o indisponibilidad, o mejor del gradiente de disponibilidad en la mente del otro (Ferro, 2004); la mente del analista va construyendo imágenes narrativas que favorecen que el sin sentido encuentre una organización posible.

En este punto retorna aquello del relato: la casa, el cuadro... todo igual, nada cambió. Un no-lugar que al ser relatado y "puesto" en el campo analítico abre un espacio en ese encuentro de modo tal que el campo cobra dinamismo, se hace entramado entre el pasado y el presente, pudiendo tejer o al menos contener en su trama la secuencia de hechos que no alcanzan a enlazarse en su historia: la locura, el dolor, la muerte, la enfermedad, la soledad.

Pensamos, en este caso particular, que el campo analítico posibilita la historización subjetivante donde la función del analista sería de potencialidad simbolizante (Hornstein, 
2000); y la de un encuentro pensante, donde el pensar no está disociado del sentir, del alojar emociones incluso turbulentas.

Proponemos como hipótesis que esos afectos -huellas de aquello no representado- son mudos para el paciente, pero son susceptibles de ser pesquisados mediante las propias percepciones/sensaciones del analista, a partir de ciertos indicadores emocionales del campo. La mente del analista, su disposición y su propio aporte representacional serán necesarios para sobreponerse al vacío y a Tánatos. Ello sugiere algo así como una conceptualización amplia de la contratransferencia. En este sentido, señalamos que:

Racker, en el 57, en uno de los estudios sobre la técnica plantea que la objetividad del analista radica en la posición que toma frente a su propia subjetividad, la contratransferencia. La verdadera objetividad es posible a partir de su desdoblamiento interno, que capacita al analista a tomarse a sí mismo como objeto de observación y análisis continuos, una posición que hoy consideramos incorporada en el encuadre interno del analista (Rappaport de Aisemberg, 2012, p.152)

Habiendo transcurrido ya un tiempo Dolores dice: “Tengo huecos, huecos... necesito reconstruir mi pasado, pero tengo pánico de ensuciar a mi mamá”. Podríamos pensar que, frente a lo nuevo del encuentro con otro en el proceso analítico y la emergencia tanto de lo nuevo como de lo antiguo, el problema es construir recursos para que eso sea pensable, recrear un encuentro pensante de esos nuevos/antiguos sucesos e historizarlos. Desde nuestro punto de vista una posible alternativa consiste en mostrar lo que (se) está haciendo, el analista debe conservar su función interpretativa asumiendo y favoreciendo la reflexividad (Green, 1995). Quizás entonces, además de un encuentro pensante, se trate también de un encuentro sentipensante.

Senti-pensante es un concepto que Fals Borda ha tomado de los ribereños colombianos. Ellos designan de este modo al lenguaje de la verdad, que se adquiere cuando pueden integrar lo que piensan y lo que sienten, la razón y el corazón. Eduardo Galeano ha hecho propio el término y lo ha popularizado a través de sus escritos. En el Libro de los abrazos, dice:

¿Para qué escribe uno, si no es para juntar sus pedazos? Desde que entramos en la Escuela o la Iglesia, la educación nos descuartiza: nos enseña a divorciar el alma del cuerpo y la razón del corazón. Sabios doctores de Ética y Moral han 
de ser los pescadores de la costa colombiana, que inventaron la palabra sentipensante para definir el lenguaje que dice la verdad. (1993, Celebración de las bodas de la razón y el corazón)

Proponemos que, el encuentro entre el analista y su paciente, en el proceso analítico, sería senti-pensante, en tanto opere como un campo que potencie la integración de lo sentido aun cuando no ha podido ser pensado y lo acoja en un espacio transicional, que no está en la mente del paciente ni tampoco en la del analista, las implica a ambas, y a su vez las excede.

En aquella trama analítica que tejía posibilidades en el presente, cada tanto se presentificaban cosas del pasado. No como recuerdos sino como "cuasi-sueños", casi como imposiciones oniroides, que la paciente contaba en sesión anteponiendo recaudos tales como: "te lo cuento, pero quisiera no saberlo". Muy de a poco saca cajas, revisa papeles, abre cajones, pero cada uno significa conocer cosas, recordar. Encuentra unos cuadernos tipo diario íntimo de su mamá con muchos relatos que lee por primera vez. Ella habla de una "orgía con los muertos". Se encuentra con amigas de su mamá que le cuentan cosas, incluso una amiga de ella... reconstruye la historia con gran pesar.

El análisis entonces, no sólo rearmaba el tejido psíquico que la repetición, comandada por la pulsión de muerte, destejió en su poder de desligadura; sino que también operaba creando un entramado capaz de contener aquello que no había podido adquirir representación (Marucco, 2007), aquello que, aun teniendo presencia en el campo, no encontraba ligaduras: entre otros, la mamá de Dolores, que en sus ropajes de madre, maestra, sobrina, viuda, nunca encontró, en sus denominaciones, nombre propio. Dolores afirmaba con intensidad emocional: “tengo pánico de ensuciar a mi mamá”. No nombrar... ¿será no ensuciar?

¿Cómo realizar la "puesta en escena" de las re-presentaciones y de lo no representado? ¿De aquello que tiene presencia como huella muda y activa? ¿Cuáles serán las transformaciones que operan para que se favorezca el pasaje desde la pura cantidad de excitación, aún no tramitada psíquicamente, hacia el sentido y su posible elaboración? ¿Cuáles son los modos en que, en el escenario analítico, se configura y permite integrar/tejer/entramar lo sentido y lo pensado?

Entendemos que el analista se va a ver obligado a aportar de sí un quantum de eros con función de ligar, para que sea posible, al decir de Galeano, “juntar sus pedazos”. Será la relación del objeto-analista con el yo-paciente la que propiciará y favorecerá la actividad de 
ligadura, y posteriormente su internalización. "Se generan así las condiciones que hacen más factibles neutralizar el predominio de la función de muerte y la consecuente liberación de la pulsión de vida que facilitará el progresivo acceso a la simbolización" (Rappaport de Aisemberg, 2012, p. 222).

Proceso de ligadura en Tramas de un encuentro sentipensante en donde el campo, como artificio o constructo en permanente estructuración y modificación, permite analizar la creaciónde ambos. Creación, re creación, continuidad...discontinuidad que permite que aquello que estaba pueda ser resignificado y en el envés de ese proceso abra a aquello inédito, subjetivo y subjetivante. Un campo que, opera en función historizante, entramando presencias/ausencias, violencias, Dolores/olvidos.

\section{Referencias Bibliográficas}

Baranger, M y W. (1969). Problemas del campo psicoanalítico. Buenos Aires: Ediciones Kargieman.

Bion, W. (1992). Seminarios clínicos y cuatro textos. Buenos Aires: Lugar Editorial.

Fals Borda, O. (2008). Sentipensante. [Archivo de video] Recuperado de https://www.youtube.com/watch?v=LbJWqetRuMo.

Ferro, A. (2004). Factores de enfermedad. Factores de curación. Buenos Aires: Lumen.

Galeano, E. (1993). El libro de los abrazos. Madrid: Siglo XXI.

Green, A. (1995). El trabajo de lo negativo. Buenos Aires: Amorrortu Editores.

Hornstein, L. (2000). Narcisismo. Autoestima, identidad, alteridad. Buenos Aires: Paidós.

Marucco, N. (2007). Entre el recuerdo y el destino: la repetición. Revista Uruguaya de Psicoanálisis; 105, 26-54. Recuperado de https://www.apuruguay.org/apurevista/2000/16887247200710502.pdf

Rappaport de Aisemberg, E. (coord.) (2012). El cuerpo en escena. Buenos Aires: Lumen. 